
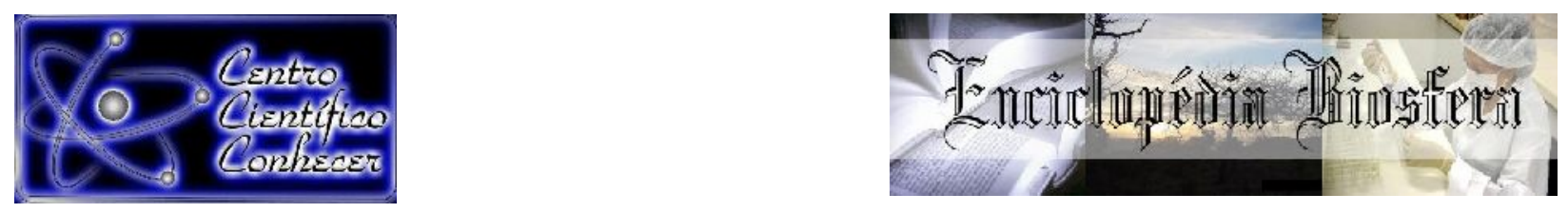

\title{
A UTILIZAÇÃO DE HISTÓRIAS EM QUADRINHOS (HQS) NO ENSINO REMOTO EMERGENCIAL DE CIÊNCIAS DA NATUREZA
}

\footnotetext{
Pedro Bruno Silva Lemos', Sandro César Silveira Jucá², Solonildo Almeida da Silva³, Anderson de Castro Lima1, Jonathan Felipe da Silva',
}

1 Doutorando em Ensino (RENOEN) pelo Instituto Federal de Educação, Ciência e Tecnologia do Ceará (IFCE), Fortaleza-CE, Brasil.

2 Doutor em Engenharia Elétrica, Professor do Instituto Federal de Educação, Ciência e Tecnologia do Ceará (IFCE), Maracanaú-CE, Brasil.

${ }^{3}$ Doutor em Educação, Professor do Instituto Federal de Educação, Ciência e Tecnologia do Ceará (IFCE), Maracanaú-CE, Brasil.

E-mail: pedrobrunolemos1990@gmail.com

Recebido em: 15/11/2021 - Aprovado em: 15/12/2021 - Publicado em: 30/12/2021 DOI: 10.18677/EnciBio_2021D1

trabalho licenciado sob licença Creative Commons Attribution-NonCommercial-NoDerivatives 4.0 International License.

\section{RESUMO}

A pandemia de COVID-19 e as medidas de distanciamento social exigiram uma maior flexibilização dos docentes, assim como a implementação de novas ferramentas ou recursos didáticos e pedagógicos que possibilitassem a manutenção do processo de ensino e de aprendizagem no modelo de ensino remoto emergencial caracterizado pela mediação tecnológica. Nesse contexto, o presente trabalho objetivou analisar, mediante revisão integrativa da literatura, a utilização de histórias em quadrinhos (HQ) como ferramenta e/ou recursos pedagógico no Ensino de Ciência da Natureza, no contexto da pandemia de COVID-19. A revisão da literatura foi focada na identificação de artigos nas bases de dados acadêmicos: Google Acadêmico e Scientific Eletronic Library Online (SciELO) do Brasil. Concluiu-se que a utilização de HQs no ensino remoto de Ciências da Natureza foi, em um maior quantitativo dos artigos analisados, centrada na elaboração desses matérias pelos próprios alunos. Nesse sentido, também se inferiu que a criação de HQs pelos alunos pode complementar a compreensão dos conteúdos abordados em sala de aula e/ou ser utilizada como uma atividade direcionada para a avaliação da aprendizagem.

PALAVRAS-CHAVE: Ensino de Ciências da Natureza. Ensino Remoto Emergencial. Pandemia. Histórias em quadrinhos.

\section{THE USE OF STORIES IN COMICS (COMICS) IN EMERGENCY REMOTE TEACHING OF NATURE SCIENCES: A LITERATURE REVIEW}

\begin{abstract}
The COVID-19 pandemic and measures of social distancing required greater flexibility from teachers, as well as the implementation of new tools or didactic and pedagogical resources that would enable the maintenance of the teaching and learning process in the emergency remote teaching model characterized by
\end{abstract}


technological mediation. In this context, this study aimed to analyze, through an integrative literature review, the use of comic books (Comic Books) as a tool and/or pedagogical resource in Nature Science Teaching, in the context of the COVID-19 pandemic. The literature review focused on identifying articles in the academic databases: Google Scholar and Scientific Electronic Library Online (SciELO) in Brazil. It was concluded that the use of comic books in remote teaching of Nature Sciences was, in a larger number of analyzed articles, focused on the elaboration of these matters by the students themselves. In this sense, it was also inferred that the creation of comic books by students can complement the understanding of the contents covered in the classroom and/or be used as an activity aimed at evaluating learning.

KEYWORDS: Comics. Nature Science Teaching. Emergency Remote Learning. Pandemic.

\section{INTRODUÇÃO}

No mês de dezembro de 2019, foram identificados, na cidade chinesa de Wuhan, os primeiros casos de uma síndrome respiratória aguda causada por um novo Coronavírus: o SARS-CoV-2 (GARCIA; DUARTE, 2020; SILVA JUNIOR et al., 2020). A COVID-19, como foi nomeada a mencionada síndrome respiratória aguda, mostrou-se altamente contagiosa e com um alto potencial de letalidade em idosos, indivíduos com comorbidades e/ou com problemas respiratórios (FEITOZA et al., 2020). Em decorrência do aumento e da disseminação do número de casos em escala mundial, no dia 11 de março de 2020, a Organização Mundial de Saúde (OMS) declarou a COVID-19 uma pandemia (GARCIA; DUARTE, 2020). Nesse contexto, a maior parte dos países implementaram medidas de restrição de acesso a voos internacionais e o fechamento de suas fronteiras, bem com medidas internas de distanciamento social com o intuito de diminuir os casos de infecção por COVID19. É importante mencionar, ainda, que a utilização de Equipamentos de Proteção Individual (EPIs), notadamente, de máscaras se tornou obrigatória para a circulação em espaços públicos (GARCIA; DUARTE, 2020; SILVA JUNIOR et al., 2020).

A pandemia de COVID-19, portanto, ocasionou profundas alterações nas mais diversas dimensões da vida em sociedade (CRUZ et al., 2020; GARCIA; DUARTE, 2020; LEMOS et al., 2021). No que diz respeito aos sistemas nacionais de educação, observa-se que a pandemia acarretou a suspensão das atividades educacionais presenciais e, consequentemente, a implementação de um modelo de ensino remoto emergencial caracterizada pela total mediação tecnológica dos processos de ensino e de aprendizagem (AMORIM; COSTA, 2020; COSTA, 2020).

$O$ modelo de ensino remoto emergencial exigiu um repentino processo de reestruturação e de adequação dos processos de ensino e de aprendizagens em todos os níveis de ensino (AMORIM; COSTA, 2020; FERREIRA et al., 2020). Por conseguinte, enfatiza-se que a inserção de novas tecnologias foi acompanhada pela adaptação de conceitos e práticas pedagógicas - elaboradas, incialmente, para o modelo presencial - para a mediação tecnológica (SANTOS JÚNIOR; MONTEIRO, 2020).

No contexto brasileiro, o modelo de ensino remoto emergencial é caraterizado pela substituição do formato presencial para o formato virtual, isto é, pela realização de aulas a partir de transmissões on-line em tempo real (AMORIM; COSTA, 2020; BRASIL, 2020; OLIVEIRA; SOUZA, 2020). Amorim e Costa, ademais, ressaltam que as atividades remotas ocorrem de forma síncrona, nos horários previstos para a 
realização das atividades presenciais. Além disso, sublinham que a utilização de plataformas ou serviços on-line de comunicação por vídeo viabilizou que as aulas fossem gravadas e assistidas de forma assíncronas (AMORIM; COSTA, 2020).

O ensino remoto emergencial também ocasionou uma progressiva adoção de novos métodos e práticas pedagógicas, bem como de recursos e ferramentas que possibilitem uma maior interação entre docentes e discentes (AMORIM; COSTA; 2020; SILVA JÚNIOR et al., 2020). Desse modo, ressalta-se que a pandemia de COVID-19 e o modelo de ensino remoto emergencial potencializaram a necessidade de adequação de metodologias que promovessem a atuação ativa dos discentes na aprendizagem ao novo contexto de mediação pelas Tecnologias da Informação e Comunicação (AMORIM; COSTA, 2020; DELFINO et al., 2020; FREITAS FILHO et al., 2021).

A pandemia de COVID-19 exigiu que os profissionais da educação elaborassem ferramentas ou métodos para se adaptarem à mediação tecnologia (AMORIM; COSTA; 2020; TEIXEIRA; BARBOSA, 2021). Nesse sentido, as HQs surgem como importantes ferramentas para proporcionar o aumento da interação e da participação dos discentes no contexto de aulas remotas, principalmente, no Ensino de Ciências da Natureza (TEIXEIRA; BARBOSA, 2021).

As medidas de distanciamento social e a utilização de tecnologias para a manutenção das aulas acarretaram, portanto, a procura por ferramentas ou recursos que proporcionem a aprendizagem e estimulem a criatividade dos alunos (SILVA JÚNIOR et al., 2020). Portanto, o uso de HQs, no contexto pandêmico, contribui para que as atividades educacionais síncronas ou assíncronas abordassem conteúdos de maneira lúdica e contextualizada (AMORIM; COSTA, 2020; DELFINO et al., 2020; TEIXEIRA; BARBOSA, 2021).

O Ensino de Ciências da Natureza é caracterizada pela necessidade de contextualização de conteúdos e conceitos científicos, bem como pela utilização de práticas pedagógicas que superem o modelo tradicional de ensino pautado na transmissão oral de conhecimento e na atuação passiva dos discentes no processo de ensino e de aprendizagem (CAVALCANTE et al., 2015; IANESKO et al., 2017; LIU et al., 2019). No processo de ensino remoto, salienta-se que essas necessidades são potencializadas pela mediação tecnológica.

Isto posto, o presente artigo tem como objetivo principal a análise e a discussão, mediante revisão integrativa da literatura, da utilização de histórias em quadrinhos (HQ) como ferramenta e/ou recursos pedagógico no Ensino de Ciência da Natureza, no contexto da pandemia de COVID-19. A definição do recorte de análise foi legitimada pelo fato das HQs oportunizarem tanto a contextualização didático-pedagógico dos conteúdos como a inserção de uma abordagem lúdica e transversal em todos os níveis e diferentes modalidades de ensino (IANESKO et al., 2017; LIU et al., 2019 ; COSTA, 2020; DELFINO et al., 2020).

A pesquisa na área de Ensino é por natureza interdisciplinar e objetiva o desenvolvimento de propostas tanto no ensino formal quanto informal (BRASIL, 2019). Destarte, destaca-se que pretendeu-se analisar o uso de HQs nos componentes curriculares das áreas de Ciências da Natureza e/ou Ciências da Natureza e suas Tecnologias, em consonância à organização disposta na Base Nacional Comum Curricular (BNCC) (BRASIL, 2018).

\section{MATERIAL E MÉTODOS}

O presente trabalho é caracterizado como um estudo de revisão integrativa da literatura, de natureza, essencialmente, exploratória e fundamentado em uma 
abordagem do tipo qualitativa. As revisões integrativas da literatura objetivam a análise e a síntese dos resultados de múltiplas pesquisas sobre um determinado tema, possibilitando, dessa forma, a identificação de possíveis lacunas nas áreas de estudos, a definição de conceitos, a revisão teórica, a análise metodológica e a obtenção de conclusões gerais acerca do tópico em revisão (MENDES et al., 2008;GALVÃO; RICARTE, 2019).

Nessa perspectiva, esse trabalho visou sintetizar e discutir os resultados de pesquisas a respeito da utilização de HQs no Ensino de Ciências da Natureza no contexto da pandemia de COVID-19. Portanto, buscou-se identificar e discutir a utilização do referido recurso didático e pedagógico no modelo de Ensino de Ciências da Natureza durante a pandemia, caracterizado pela mediação do processo de ensino e de aprendizagem por tecnologias digitais de informação e comunicação.

A identificação e a seleção da literatura científica que subsidiou a elaboração dessa revisão ocorreram mediante busca on-line nas seguintes bases de dados: Google Acadêmico e Scientific Eletronic Library Online (SciELO) do Brasil. O levantamento dos estudos foi pautado na utilização dos seguintes descritores e em português: "HISTÓRIAS EM QUADRINHOS" AND "PANDEMIA", "HISTÓRIAS EM QUADRINHOS" AND "PANDEMIA", "HISTÓRIAS EM QUADRINHOS" AND "COVID19" e "HISTÓRIA EM QUADRINHOS" AND "COVID 19".

Após a identificação, os estudos foram selecionados de acordo com os critérios de inclusão e exclusão. Para a seleção da literatura, utilizou-se os seguintes critérios de inclusão: artigos científicos, anexados nas bases de dados selecionadas e disponíveis para leitura na íntegra, que abordaram temáticas associadas ao objetivo desse estudo, no idioma português e que foram publicados entre os anos de 2020 e 2021. Foram excluídos da análise dissertações, monografias, teses, artigos que não discutiam temáticas relacionadas à pesquisa, artigos que não estavam disponíveis para leitura na integra de forma gratuita, artigos de revisão da literatura, artigos em outros idiomas e outras publicações não classificadas como artigos científicos, por exemplo, textos de opinião, livros e capítulos de livros, editoriais e resenhas.

Selecionou-se artigos científicos publicados em 2020 e 2021, por ser o período temporal que engloba a caracterização da COVID-19 como pandemia, pela Organização Mundial de Saúde (OMS), assim como a adoção de medidas de distanciamento social. Cabe mencionar que o referido período temporal também foi caracterizado pela implementação do modelo de ensino remoto como estratégia para manutenção das atividades de educacionais no contexto pandêmico.

A literatura científica selecionada, em um primeiro momento, foi lida na íntegra para a construção do corpus em análise nesse estudo. Em paralelo, realizou-se a extração de dados e o preenchimento de uma planilha, elaborada pelos autores, utilizada na organização e na síntese dos principais resultados.

Por fim, salienta-se que a identificação e a seleção de artigos científicos ocorreram no mês de setembro de 2021. Ademais, a leitura na íntegra e a organização dos principais resultados dos trabalhos selecionados foram realizadas no decorrer dos meses de setembro e outubro de 2021.

\section{HQS: SURGIMENTO, CARACTERIZAÇÃO E INSERÇÃO NO CONTEXTO EDUCACIONAL}

A representação de narrativas por meio de desenhos e/ou imagens permeia a história humana, desde as pinturas rupestres em cavernas no decorrer da préhistória até os dias atuais caracterizados pela produção imagética (BIBE-LUYTEN, 
1985; ALVES, 2018). No entanto, Bibe-Luyten (1985), Santos e Ganzarolli (2011), Vergueiro (2010) e Xavier (2017) salientam que o modelo de História em Quadrinhos $(\mathrm{HQ})$ que é conhecido atualmente é resultante do processo de desenvolvimento da imprensa moderna e dos meios de comunicação de massa.

Bibe-Luyten (1985), Santos e Ganzarolli (2011), Santos e Vergueiro (2012), Vergueiro (2010) e Xavier (2017) corroboram que as HQs surgem nas empresas jornalísticas estadunidenses nas últimas décadas do século XIX. Todavia, não há um certo consenso a respeito da definição do autor da primeira HQ (BIBE-LUYTEN, 1985; SANTOS; GANZAROLLI, 2011). De maneira geral, a literatura pontua duas características que condicionaram o surgimento das $\mathrm{HQs}$, a saber: a caracterização como produto direcionado para a comunicação de massa e a existência de processos modernos de impressão e reprodução gráfica (BIBE-LUYTEN, 1985; SANTOS; GANZAROLLI, 2011; XAVIER, 2017).

No que diz respeito à sua estrutura, observa-se que as $H Q$ s são constituídas a partir da utilização de dois códigos de signos diferentes e duas diferentes formas de arte, isto é, a imagem (desenho) e a linguagem escrita (literatura) (BIBELUYTEN, 1985; VERGUEIRO, 2010; XAVIER, 2017). Para Bibe-Luyten (1985), essa constituição múltipla das HQs retrata o contexto moderno caracterizado pela inexistência ou diminuição de divisões entre diferentes formas de expressão artística.

A organização das HQs é sequencial e dividida em quadros (quadrinhos) que constituem uma unidade narrativa denominada vinheta (VERGUEIRO, 2010). O modelo de criação adotado no ocidente é pautado na organização das vinhetas de cima para baixo e na sequência de leitura das narrativas da esquerda para a direita (VERGUEIRO, 2010).

Os quadrinhos, normalmente, possuem um formato retangular, porém algumas HQs podem apresentar diferentes formatos (VERGUEIRO, 2010). É importante mencionar que o formato dos quadrinhos pode ser utilizado como um efeito visual para retratar os acontecimentos apresentados nas narrativas. Desse modo, Santos e Ganzarolli (2011) destacam que é comum algumas HQs de superheróis apresentarem quadrinhos em formatos mais arrojados.

Além da organização da narrativa em quadrinhos, ressalta-se que a inserção de "balões" é um elemento fundamental para a organização e compreensão das HQs (BIBE-LUYTEN, 1985). Os balões, enquanto elementos imprescindíveis de uma $H Q$, podem registrar os diálogos entre personagens, as mudanças de humores e as expressões de emoções e sentimentos (BIBE-LUYTEN, 1985). Nesse sentido, reforça-se que os balões complementam e significam as imagens.

O formato dos balões pode mudar de acordo como o objetivo do texto que será apresentado e dos efeitos visuais ou sonoros que serão inseridos em cada quadrinho (BIBE-LUYTEN, 1985). Desse modo, cabe mencionar que a utilização de onomatopeias para representar ruídos e sons é uma relevante característica do modelo de linguagem adotado nas HQs (BIBE-LUYTEN, 1985).

Apesar da diferença de nomenclatura adotada em cada contexto nacional, Bibe-Luyten (1985) e Vergueiro (2010) constatam que, a partir da década de 1930, as HQs tornaram-se um meio de comunicação de massa difundido em todo o mundo. Nesse contexto, paulatinamente as HQs tornaram-se uma popular fonte de entretenimento para indivíduos de diferentes faixas e passaram a ser inseridas em diversas outras áreas, por exemplo, nos ambientes educacionais como ferramentas pedagógicas nos processos de ensino e de aprendizagem, com inspiração para 
produção de filmes e séries, e como artefatos culturais que caracterizam determinados grupos sociais.

Carlan et al. (2013) indicam que, no contexto brasileiro, a inserção de HQs nos ambientes educacionais tem seu início no decorrer da década de 1980. Todavia, Silva Júnior et al. (2020) destacam que esse processo de inserção foi lento e condicionado pela existência de preconceitos relacionados a utilização das HQs como ferramenta pedagógica.

Alves (2018) assinala que muitos professores e pais de alunos compreendiam as HQs como leituras inferiores que poderiam afetar o desempenho intelectual dos leitores. Sobre essa mesma questão, Vergueiro (2010) complementa que as opiniões preconceituosas a respeito das HQs eram nutridas pelo desconhecimento da sua utilização no contexto educacional.

Silva Júnior et al. (2020) constatam que progressivamente os preconceitos foram superados e as HQs começaram a ser inseridas em textos e livros didáticos. Para Amorim e Costa (2020), Freitas Filho et al., (2021) Santos e Vergueiro (2012) e Silva Júnior et al. (2020), as HQs se tornaram ferramentas pedagógicas aplicáveis em diferentes níveis de ensino e áreas de conhecimento. À vista disso, Melo et al. (2013) comentam que as HQs passaram a ser caracterizadas como:

[...] recursos com imenso potencial pedagógico capaz de articular-se aos vários campos do conhecimento, propiciando uma forma de expressão da comunicação artística e literária atual, em que é possível relacionar as vivências e experiências do educando com o contexto teórico. (MELO et al., p. 267).

Entretanto, Santos e Vergueiro (2012), ratificam que a disponibilidade de HQs nos ambientes escolares não garante a adequada inserção destas no processo de ensino e de aprendizagem. Desse modo, os citados autores frisam que a utilização pedagógica dessas ferramentas pressupõe que os docentes reflitam, de maneira crítica, acerca: da indicação da faixa etária da HQs, da necessidade de adequação da obra aos conteúdos abordados, da compreensão dos elementos que caracterizam a linguagem das $\mathrm{HQs}$ e da adequabilidade da extensão da $\mathrm{HQ}$ com o objetivo pedagógico proposto (SANTOS; VERGUEIRO, 2012).

Em adicional, é importante frisar que as duas primeiras décadas do século XXI são pontuadas por uma ampla popularização das HQs para diferentes faixas etárias. Nesse contexto, Camargo e Rivelini-Silva (2017), lanesko et al. (2017) e Santos e Vergueiro (2012) inferem que diversos autores têm discutido a utilização pedagógicas dessa ferramenta em diferentes cenários educacionais.

\section{HQS NO ENSINO DE CIÊNCIAS DA NATUREZA}

Liu et al. (2019) comentam que, de maneira geral, a sociedade caracteriza o Ensino de Ciências pela existência de conteúdos difíceis e distanciados da realidade e do cotidiano vivenciado pelos educandos. Nessa perspectiva, lanesko et al., também mencionam que as dificuldades imputadas ao ensino de Ciências estão relacionadas à exigência da aprendizagem de conhecimento científicos e matemáticos para a resolução e/ou interpretação de problemas os educandos.

Isto posto, lanesko et al. (2017), observaram que os conteúdos abordados no Ensino de Ciências devem ser explicados de uma maneira que facilite a aprendizagem e que, consequentemente, enseje que o discente reflita criticamente a respeito das atividades e temáticas propostas. Entretanto, Camargo e Rivelini-Silva (2017) e Cavalcante et al. (2015) atestam que prevaleceu por décadas um 
paradigma tradicional no Ensino de Ciências centrado em práticas convencionais, por exemplo, na transmissão oral de conceitos científicos e abstratos e na recepção passiva dos conteúdos pelos discentes.

Cavalcante et al. (2015) também pontuam que esse modelo de ensino tradicional contribuía para a reprodução mecânica dos conteúdos teóricos e para o aumento de dificuldades na aprendizagem nas disciplinas das Ciências da Natureza. Nessa perspectiva, a apresentação oral $e$ as demonstrações teóricas descontextualizadas contribuíam para uma compreensão parcial dos conteúdos de Ciências (CAMARGO; RIVELINI-SILVA, 2017).

Diante desse cenário caracterizado pela dificuldade em compreensão dos conteúdos, Camargo e Rivelini-Silva (2017) salientam que as pesquisa na área de Ensino de Ciências têm focado na definição de metodologias e/ou ferramentas que viabilizem uma ruptura com o modelo tradicional de ensino, assim como contribua para a inserção ativa dos discentes no processo de ensino e aprendizagem (CAMARGO; RIVELINI-SILVA, 2017). Em adicional, Cavalcante et al. (2015) ressaltam que as mudanças sociais e a progressiva inserção de novas tecnologias no contexto escolar exigem que os professores repensem suas práticas pedagógicas.

De maneira complementar, lanesko et al. (2017) argumentam que a resolução das citadas dificuldades enfrentadas pelo Ensino de Ciências pressupõe a aplicação de abordagens e recursos didáticos que possibilitem a superação do modelo de ensino estritamente tradicional e a desmistificação dos conteúdos científicos. Desse modo, os mencionados autores aduzem que a utilização de HQs pode contribuir para a aprendizagem dos conteúdos e, consequentemente, para a melhoria do processo de ensino e de aprendizagem (IANESKO et al., 2017).

No contexto atual, verifica-se uma progressiva e relevante utilização de HQs nos livros didáticos da área de Ciências da Natureza destinados ao Ensino Fundamental e ao Ensino Médio (CAMARGO; RIVELINI-SILVA, 2017). Essa utilização é justificada pelo fato de as $\mathrm{HQs}$ oportunizarem a contextualização e a expansão dos conceitos e a formação de novos conceitos mediante a interação das imagens com a linguagem verbal (CAMARGO; RIVELINI-SILVA, 2017).

Esse processo de inserção das HQs nos materiais didáticos e nos ambientes de educação formal teve seu início na década de 1990, em específico, após a promulgação da Lei de Diretrizes e Bases da Educação Nacional (LDB) (LIU et al., 2019). Como foi mencionado, o início do uso pedagógico das HQs remonta à década de 1980, porém a LDB fomentou a utilização de produtos culturais na educação formal (LIU et al., 2019). Logo, a partir da promulgação da LDB, as HQs passaram a ser compreendidas como um recurso didático e não apenas um produto voltado para o entretenimento (LIU et al., 2019).

As HQs, portanto, são recursos pedagógicos que, em decorrência da sua especificidade lúdica, imagética e linguística, podem contribuir para que os alunos reflitam a respeito dos conteúdos ou conceitos abordados (IANESKO et al., 2017). Ao analisar o uso de HQs no Ensino de Química, lanesko et al. (2017) destacam que o referido recurso pedagógico pode ser empregado na diminuição do distanciamento do aluno com o conteúdo abordado, uma vez que auxilia, por meio da sua linguagem específica, a compressão dos assuntos discutidos em sala de aula.

Freitas Filho et al. (2021) sobressaltam que as HQs são importantes ferramentas didáticas, pois aliam a abordagem lúdica dos conteúdos curriculares ao desenvolvimento do interesse pela leitura. Desse modo, os autores indicam a 
elaboração de HQs em conjunto com outras ferramentas didáticas para a avaliação da aprendizagem dos alunos (FREITAS FILHO et al., 2021).

Silva Júnior et al. (2020) constataram que as HQs são importantes instrumentos para a aplicação de metodologias ativas no Ensino de Ciências da Natureza, pois contribuem para que o aluno atue de maneira autônoma no processo de aprendizagem. Os mencionados autores ainda colocam que as HQs apresentam uma narrativa que relaciona uma linguagem e linguística com os conteúdos ou conhecimentos científicos, o que amplifica a aquisição de conhecimento pelos alunos (SILVA JÚNIOR et al., 2020).

Em consonância com os argumentos expostos, Silva Júnior et al. (2020), ainda, frisam que as $\mathrm{HQs}$ são ferramentas ou recursos pedagógicos que oportunizam a criação de:

[...] situações de instrução que viabilizem a aproximação crítica dos leitores com a realidade, ao aperfeiçoarem suas práticas de leitura, produção textual e aquisição de novos conhecimentos, as HQs, de acordo com as temáticas trazidas em cada uma dessas histórias, possibilitam aos alunos a ampliação da capacidade de expressarem suas ideias, anseios, dúvidas e percepções do contexto em que estão inseridos e desenvolver o letramento científico (SILVA JÚNIOR et al, 2020).

Os citados autores também pontuam que o uso de HQs no Ensino de Ciências da Natureza e nas demais áreas de conhecimento propicia que o aluno atue na construção de uma aprendizagem significativa, uma vez que as especificidades do mencionado gênero textual estimulam a curiosidade e a criatividade dos alunos (SILVA JÚNIOR et al.,, 2020). Além disso, frisam que as HQs potencializam as estratégias que objetivam fomentar 0 desenvolvimento de competências leitoras (SILVA JÚNIOR et al., 2020).

Cabe mencionar que as HQs estão inseridas no cotidiano de alunos de diferentes faixas etárias e podem ser acessadas nos mais variados formatos. Assim sendo, Teixeira e Barbosa (2021) destacam que a produção de HQs pode aliar a produção textual à inserção de recursos ou ferramentas tecnologias no ambiente escolar. Os autores ainda observam a adequabilidade pedagógica do uso de HQs em propostas interdisciplinares, notadamente, nas disciplinas de Língua Portuguesa e Biologia.

Venturi et al. (2021) atestam a importância das HQ para o Ensino de Ciências, pois contribuem para a implementação de propostas de ensino que objetivem a flexibilização dos conceitos científicos ou conteúdos curriculares. Nesse sentido, é importante mencionar que Camargo e Rivelini-Silva (2017) apresentam uma relevante revisão da literatura que evidencia o uso de HQs no Ensino de Ciências.

\section{A UTILIZAÇÃO DE HQS NO ENSINO REMOTO DE CIÊNCIAS DA NATUREZA}

Após utilização dos descritores, identificou-se um total de quarenta e oito artigos que abordavam a utilização de HQs no ensino remoto emergencial. Em seguida, foi realizada a leitura na íntegra de todos os quarenta e oito artigos objetivando-se a identificação dos estudos que discutiam, de maneira específica, a utilização de HQs no Ensino de Ciências da Natureza no contexto da pandemia de COVID-19.

No momento seguinte à leitura do corpus de trabalhos selecionados, identificou-se um total de dez artigos científicos que discorriam a respeito da inserção de HQs como recursos pedagógicos e didáticos no Ensino de Ciências da Natureza. Cabe mencionar que todos os dez artigos abordavam experiências ou ENCICLOPÉDIA BIOSFERA, Centro Científico Conhecer - Jandaia-GO, v.18 n.38; p. 8 
propostas implementadas no modelo de ensino remoto emergencial, conforme dispostos no QUADRO 1.

QUADRO 1 - Relação de artigos selecionados

\begin{tabular}{|c|c|c|c|}
\hline Autor(es) & Título & Periódico & $\begin{array}{c}\text { Ano de } \\
\text { publicação }\end{array}$ \\
\hline OLIVEIRA et al., 2021 & $\begin{array}{c}\text { Educação Ambiental: ações e experiências em espaço } \\
\text { educativo não-formal em tempos de pandemia }\end{array}$ & $\begin{array}{c}\text { Revista } \\
\text { Macambira } \\
\end{array}$ & 2021 \\
\hline SALES, 2020 & $\begin{array}{c}\text { Vírus: sequência didática para o Ensino de Ciências } \\
\text { pós pandemia }\end{array}$ & $\begin{array}{l}\text { Experiências em } \\
\text { Ensino de } \\
\text { Ciências } \\
\end{array}$ & 2021 \\
\hline FRAGUAS et al., 2021 & $\begin{array}{c}\text { Relato de uma experiência no ensino virtual de } \\
\text { Química Orgânica: revisitando diferentes estratégias } \\
\text { pedagógicas }\end{array}$ & $\begin{array}{l}\text { Experiências em } \\
\text { Ensino de } \\
\text { Ciências } \\
\end{array}$ & 2021 \\
\hline $\begin{array}{l}\text { SILVA JÚNIOR et al., } \\
2020\end{array}$ & $\begin{array}{l}\text { Utilização de história em quadrinhos como estratégia } \\
\text { no ensino de ciências da natureza }\end{array}$ & $\begin{array}{c}\text { Revista } \\
\text { Intersaberes }\end{array}$ & 2020 \\
\hline $\begin{array}{l}\text { AMORIM; COSTA, } \\
2020\end{array}$ & $\begin{array}{l}\text { Estratégias para o ensino da Covid-19 utilizando } \\
\text { aplicativos de histórias em quadrinhos. }\end{array}$ & $\begin{array}{c}\text { Revista } \\
\text { Intersaberes }\end{array}$ & 2020 \\
\hline $\begin{array}{l}\text { GASPERI; EMMEL, } \\
2021\end{array}$ & $\begin{array}{l}\text { Produção de Histórias em Quadrinhos on-line na } \\
\text { abordagem interdisciplinar de ensino de Biologia e } \\
\text { Linguagens. }\end{array}$ & $\begin{array}{l}\text { Revista Letras } \\
\text { Raras }\end{array}$ & 2021 \\
\hline $\begin{array}{l}\text { CUSTÓDIO et al., } \\
2021\end{array}$ & $\begin{array}{c}\text { Metodologias ativas com o uso de TIC mistas nos } \\
\text { processos de ensino e de aprendizagem de HC com } \\
\mathrm{HQ}\end{array}$ & $\begin{array}{c}\text { Cadernos de } \\
\text { Educação Básica }\end{array}$ & 2021 \\
\hline $\begin{array}{c}\text { TEIXEIRA; } \\
\text { BARBOSA, } 2021 \\
\end{array}$ & $\begin{array}{c}\text { Educação sexual no ensino básico: o estudante de } \\
\text { medicina como educador }\end{array}$ & \begin{tabular}{|c|} 
Revista Eletrônica \\
Acervo Saúde \\
\end{tabular} & 2021 \\
\hline $\begin{array}{l}\text { PREUSSLER; } \\
\text { FUCKS, } 2021\end{array}$ & $\begin{array}{c}\text { "Químiemcasa": aspectos de um processo de ensino } \\
\text { para a aprendizagem de Química em épocas de } \\
\text { pandemia }\end{array}$ & $\begin{array}{l}\text { Research, Society } \\
\text { and Development }\end{array}$ & 2020 \\
\hline SILVA et al., 2021 & $\begin{array}{l}\text { A reciclagem de sucata eletrônica como tema gerador } \\
\text { de práticas educativas no nível médio do Ensino de } \\
\text { Química. }\end{array}$ & $\begin{array}{l}\text { Revista Insignare } \\
\text { Scientia-RIS }\end{array}$ & 2021 \\
\hline
\end{tabular}

Fonte: Os autores (2021)

É importante mencionar que, em decorrência do período de surgimento e desenvolvimento da pandemia de COVID-19 e, consequentemente, de implementação do modelo remoto de ensino emergencial, os artigos foram publicados nos anos de 2020 e 2021. Ao analisar os artigos publicados em 2021, constata-se que, considerando o processo de retomada das atividades presenciais na Educação Básica, algumas propostas podem ser implementadas nos modelos de ensino remoto emergencial e/ou presencial.

Observou-se que os artigos selecionados abordavam propostas de utilização de HQs direcionadas e/ou implementadas no contexto do Ensino de Ciências da Natureza na Educação Infantil (OLIVEIRA et al., 2021), na Educação Profissional Técnica de Nível Médio (SALES, 2020), no Ensino Fundamental (SILVA JÚNIOR et al., 2020 ; CUSTÓDIO et al., 2021; GASPERI; EMMEL, 2021; FRAGUAS et al., 2021), no Ensino Médio (AMORIM; COSTA, 2020; PREUSSLER; FUCKS, 2021; SILVA et al., 2021; TEIXEIRA; BARBOSA, 2021). Assim, destaca-se que o maior quantitativo de propostas de utilização de HQs direcionadas para o Ensino de Ciências da Natureza no Ensino Fundamental e no Ensino Médio pode ser relacionado à progressiva inserção do referido nos livros didáticos, conforme elencado por Camargo e Rivelini-Silva (2017) (Ver GRÁFICO 1). 
GRÁFICO 1 - Artigos selecionados por etapa ou modalidade educacional

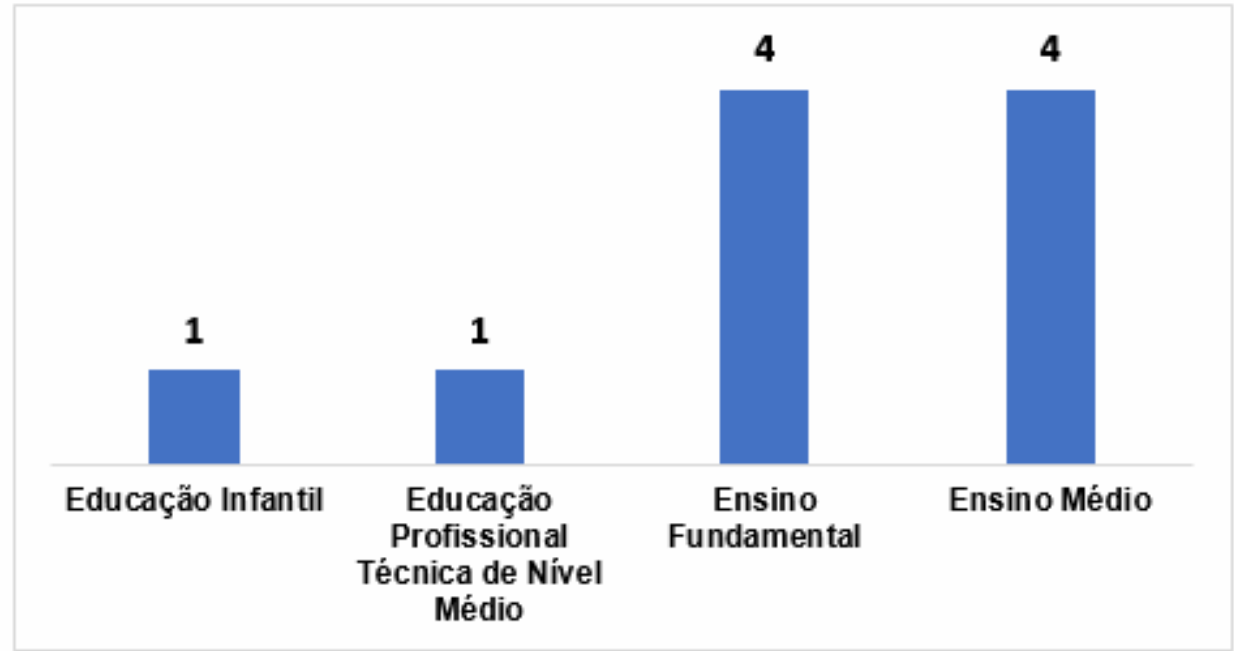

Fonte: Os autores (2021)

No que diz respeito ao componente curricular, verificou-se, em decorrência do maior quantitativo de propostas direcionadas para o Ensino Fundamental, um predomínio da utilização de HQs na disciplina de Ciências (SILVA JÚNIOR et al., 2020 ; CUSTÓDIO et al., 2021; GASPERI; EMMEL, 2021; FRAGUA et al., 2021) (Gráfico 2). No entanto, se destaca a utilização do referido recurso didático na disciplina de Química (SALES, 2020; PREUSSLER; FUCKS, 2021; SILVA et al., 2021) e na disciplina de Biologia (AMORIM; COSTA, 2020), assim como em duas propostas interdisciplinares: Oliveira et al. (2021) discorrem a respeito da uma proposta voltada para a Educação Ambiental em espaços não-formais e Teixeira e Barbosa (2021) analisam uma proposta direcionada para as disciplinas de Biologia e Língua Portuguesa (GRÁFICO 2).

GRÁFICO 2 - Artigos analisados por componente curricular

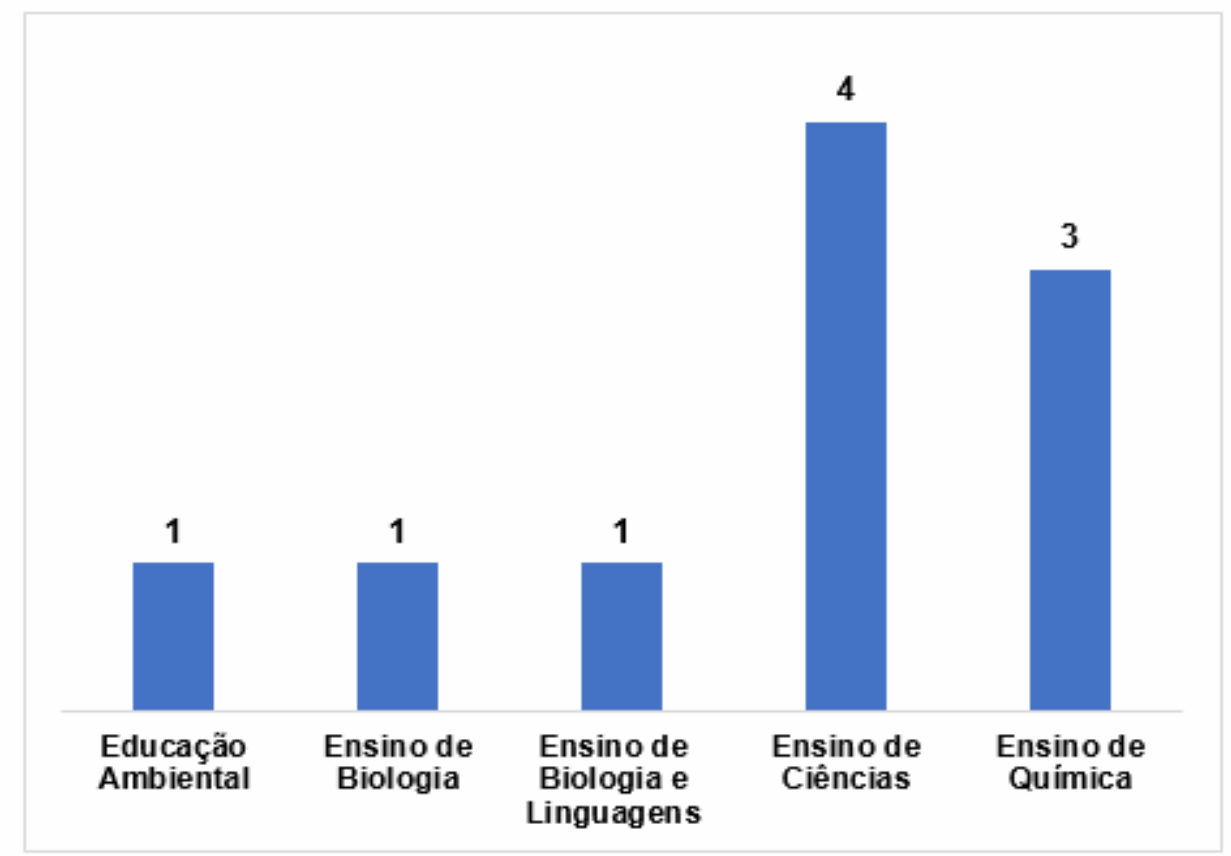

Fonte: Os autores (2021) 
Isto posto, a seguir, discorre-se, de maneira resumida, acerca de cada artigo selecionado, pontuando-se os objetivos que orientaram o uso de HQs nas propostas pedagógicas desenvolvidas, bem como as possíveis conclusões de cada estudo. Adicionalmente, pontua-se que os artigos foram organizados de acordo com o componente curricular para o qual a proposta de uso de HQs foi direcionada.

\section{HQs na Educação Ambiental}

Oliveira et al. (2021) abordam as especificidades da Educação Ambiental em espaços não-formais, no contexto do ensino remoto emergencial. Trata-se de um relato de experiencia a respeito das atividades remotas do Projeto "Educação Ambiental é fundamental!" (OLIVEIRA et al., 2021). Dentre as ações previstas para a realização do citado projeto, os autores realçaram a inserção da criação de histórias no ensino da Educação Ambiental (OLIVEIRA et al., 2021).

Objetivando a conscientização ambiental dos participantes do mencionado projeto, Oliveira et al. (2021) adotam a elaboração de histórias em quadrinhos que discutisse temáticas relacionados ao meio ambiente. Segundo os autores, a análise das respostas dos estudantes que participaram das ações do projeto evidenciou, de maneira unânime, a preferência pela elaboração de HQs. Nesse sentindo, os autores apontam que o uso de HQs propicia a reflexão acerca da "[...] questão da importância do lúdico, assim como da linguagem imagética como possibilidades para ampliar a discussão da Educação Ambiental na educação infantil" (OLIVEIRA et al., 2021, p. 9).

Portanto, os referidos autores acentuaram que a utilização de HQs se mostrou uma importante estratégia metodológica para o ensino da Educação Ambiental, pois ensejou a contextualização didático-pedagógica e a aprendizagem dos conteúdos de maneira lúdica e transversal (OLIVEIRA et al., 2021). Em adicional, constatam que a potencialidade de ações educativas fundamentadas na utilização de HQs para a divulgação de temáticas relacionadas à Educação Ambiental.

\section{HQs no Ensino de Biologia}

Amorim e Costa (2020) analisam, no contexto do ensino remoto emergencial, a utilização de aplicativos para criação de $\mathrm{HQ}$ como estratégia pedagógica para o ensino sobre a COVID-19. Os autores consideram que as HQs digitais podem contribuir para a interação entre docentes e discentes nos momentos assíncronos (AMORIM; COSTA, 2020). Ademais, relevam que a criação de HQs em aplicativos pode ser utilizada uma estratégia pedagógica implementada tanto no modelo de ensino híbrido como no modelo de ensino presencial (AMORIM; COSTA, 2020).

A definição dos aplicativos utilizados na produção de HQs foi realizada no serviço de distribuição digital de aplicativos Google Play (AMORIM; COSTA, 2020). Em um primeiro momento, Amorim e Costa (2020) selecionaram três aplicativos gratuitos entre os mais baixados pelo público do mencionado serviço on-line, a saber Marvel Comics, Comic\&MemeCreator, e Comica- Transforme suas fotos em quadrinhos.

Após realizarem o download e a análise dos três aplicativos, os autores definiram o Comica-Transforme suas fotos em quadrinhos como o mais adequado para a criação de HQs no contexto do ensino remoto emergencial (AMORIM; COSTA, 2020). Para os autores, a escolha foi justificada pelo fato do aplicativo Comica-Transforme suas fotos em quadrinhos ser intuito e possuir as configurações na língua portuguesa (AMORIM; COSTA, 2020). 
A partir de entrevistas com professores de Biologia, os autores sublinham que as estratégias de ensino que prevejam a utilização de HQs devem considerar a faixa etária da $\mathrm{HQ}$ abordada, bem como a contextualização desta com o ensino de Biologia (AMORIM; COSTA, 2020). Os autores também identificam a importância de o professor definir se as atividades serão individuais ou em grupos e as questões relacionadas o acesso dos discentes aos recursos tecnológicos necessárias para a realização das atividades planejadas (AMORIM; COSTA, 2020).

\section{HQs no Ensino de Biologia e Linguagens}

Teixeira e Barbosa (2021) analisam a realização de uma atividade interdisciplinar nas aulas remotas de Redação e Biologia de uma instituição pública. A atividade consistiu na elaboração de HQs utilizando-se recursos digitais e objetivou identificar se os alunos do Ensino Médio elaborariam trabalhos que apresentassem as características do gênero textual $\mathrm{HQ}$ e articulariam uma narrativa com os conceitos científicos estudados (TEIXEIRA; BARBOSA, 2021).

Como tema central para a elaboração das HQs, definiu-se as funções e características das organelas celulares (TEIXEIRA; BARBOSA, 2021). Para os autores, a atividade permitiu que os alunos empregassem diferentes linguagens na produção do texto e na intepretação dos conceitos científicos para as especificidades textuais do gênero HQ (TEIXEIRA; BARBOSA, 2021). De maneira complementar, os autores salientam que a utilização de HQs é uma estratégia pedagógica eficaz para a construção de conhecimento científico e contextualização de conceito abstratos complexos aplicados à Biologia, pois viabilizam a aplicação destes em narrativas com situações concretas (TEIXEIRA; BARBOSA, 2021).

No que diz respeito à realização da atividade, os autores ressaltam a importância de se considerar o domínio e a disponibilidade dos recursos tecnológicos para elaboração das HQs (TEIXEIRA; BARBOSA, 2021). Nesse sentido, destacam que a principal dificuldade enfrentada no decorrer da atividade esteve relacionada ao acesso aos dispositivos necessário para elaboração das HQs, por exemplo, celulares, tablets ou computadores (TEIXEIRA; BARBOSA, 2021).

Os autores avultam que outra dificuldade enfrentada esteve relacionada à falta de conhecimento a respeito do manuseio de ferramentas tecnológicas (TEIXEIRA; BARBOSA, 2021). Cabe mencionar que essa dificuldade também é enfrentada pelos docentes que não receberam treinamentos ou capacitações para a inserção no modelo de ensino totalmente mediado pelas TICs (TEIXEIRA; BARBOSA, 2021)

Outra questão pontuada pelos autores foi a possibilidade de utilização de HQs em propostas interdisciplinares (TEIXEIRA; BARBOSA, 2021). Isto posto, os autores enfatizam que a estratégia pedagógica realizada contribuiu para que os alunos, a partir da produção de textos do gênero $\mathrm{HQ}$, desenvolvessem a criatividade e abordassem conceitos científicos específicos da Biologia de maneira interdisciplinar e contextualizada com as narrativas propostas (TEIXEIRA; BARBOSA, 2021).

Em relação à avaliação dos trabalhos, os autores ressaltam que, além dos aspectos relacionados à revisão da ortografia e da gramática, o professor deve estabelecer se os trabalhos apresentam as características do gênero HQ, bem como se os conceitos científicos e conteúdos solicitados foram apresentados nas narrativas produzidas de maneira correta (TEIXEIRA; BARBOSA, 2021). A partir dessa perspectiva, os autores sobrelevam que os alunos que participaram da atividade conseguiram elaborar HQs adequadas às especificidades do citado gênero 
textual e discutiram os conceitos biológicos de forma correta (TEIXEIRA; BARBOSA, 2021).

\section{HQs no Ensino de Ciências}

Custódio et al. (2020) retratam a experiência de um projeto a respeito do desenvolvimento sexual voltado para aluno do Ensino Básico, realizado no contexto do ensino remoto emergencial. $O$ projeto foi executado por discentes de medicina e sua realização foi mediada por plataformas digitais (CUSTÓDIO et al., 2021).

Juntamente com os professores do Ensino Básico, os autores elaboram um vídeo acerca das alterações físicas que ocorrem na puberdade, bem como uma aula que discutia como as crianças respondem às mudanças corporais durante 0 crescimento (CUSTÓDIO et al., 2021). Em adicional, foi produzia uma HQ sobre gravidez na adolescência (CUSTÓDIO et al., 2021).

A HQ retrata a história de uma adolescente que vai à Unidade Básica de Saúde (UBS), pois suspeita que está grávida (CUSTODIO et al., 2021). O material foi elaborado na plataforma Pixton e disponibilizado no formato de conteúdo digital (CUSTÓDIO et al., 2021). Para os autores, a utilização da HQ objetivou fornecer aos adolescentes informações quanto ao direito de atendimento nas UBS em caso de situações de risco, além de possibilitar as discussões que foquem a gravidez na adolescência e os métodos concepcionais (CUSTÓDIO et al., 2021). Isto posto, notou-se que o trabalho de Custódio et al. (2020) evidencia a utilização de HQs nas discussões específicas da educação sexual de jovens.

Gasperi e Emmel (2021) analisaram a utilização de HQs para a implementação de metodologias ativas no Ensino de Ciências, nos anos finais do Ensino Fundamental. A proposta desenvolvida pelos autores abordou temáticas relacionadas à História da Ciência, especificamente, às trajetórias de mulheres pesquisadoras que tiveram destaque em diferentes áreas de conhecimento (GASPERI; EMMEL, 2021).

Em um primeiro momento, foi elaborado um roteiro que subsidiou a produção da $\mathrm{HQ}$ "Estrutura do DNA", mediante utilização da plataforma CANVA, que apresentava a vida e as contribuições científicas de Rosalind Franklin (GASPERI; EMMEL, 2021). A HQ foi disponibilizada para os alunos em formato PDF e adaptada para o formato em vídeo que foi disponibilizado para acesso na plataforma YouTube (GASPERI; EMMEL, 2021).

Após o momento destinado para leitura da $\mathrm{HQ}$ ou para visualização da narrativa em vídeo no YouTube, os autores aplicaram um questionário sobre o assunto tratado na $\mathrm{HQ}$ e solicitaram que cada aluno elaborasse sua própria narrativa em quadrinhos que discutisse os assuntos estudados na $\mathrm{HQ}$ e nas demais atividades (GASPERI; EMMEL, 2021). A partir da criação de HQs, os alunos puderam refletir acerca dos conteúdos abordados de maneira criativa. Ademais, a elaboração de HQs contribuiu para que os alunos assumissem um papel de protagonistas da aquisição de conhecimento, bem como potencializou o diálogo entre docentes e discentes (GASPERI; EMMEL, 2021).

No que diz respeito aos desenhos, os autores ressaltam que apenas uma aluna produziu uma $\mathrm{HQ}$ que retratasse uma cientista mulher, o que reflete a predominância da concepção de uma Ciência excessivamente masculina (GASPERI; EMMEL, 2021). No entanto, observam que a proposta de utilização de HQs no ensino de História da Ciência pode contribuir para o fomento de discussões no tocante à importância de contribuições de pesquisadoras e cientistas (GASPERI; EMMEL, 2021). 
Fraguas et al. (2021) propõe uma sequência didática para o estudo dos vírus. Para tanto, os autores objetivam a construção da sequência didática englobe a utilização de recursos tecnológicos, questionários e rodas de conversas, assim como a elaboração de HQs (FRAGUAS et al., 2021).

O objetivo principal da proposta elaborada pelos autores é promover o estudo interdisciplinar dos vírus e da transmissão de viroses, bem como da utilização de vacinas e da execução de medidas direcionadas para a diminuição da propagação de doenças ocasionadas por vírus (FRAGUAS et al., 2021). A sequência didática é organizada em oito aulas que devem ser realizadas de forma interdisciplinar e que enfatizam a pandemia de COVID-19 como tema central das atividades propostas (FRAGUAS et al., 2021).

A sexta aula da sequência didática prevê uma atividade interdisciplinar com as disciplinas de Artes e Língua Portuguesa fundamentada na elaboração de HQs que abordem as medidas profiláticas adotadas para a diminuição do contágio de doenças que tenham vírus e bactérias como agentes patógenos (FRAGUAS et al., 2021). Os autores propõem que a $H Q$ seja elabora na forma de desenho colorido que deve possuir, pelo menos, oito quadrinhos (FRAGUAS et al., 2021).

Os autores salientam que o docente deve solicitar, com uma certa antecedência, que os alunos organizem o material necessário para a elaboração das HQs (FRAGUAS et al., 2021). Além disso, destaca-se a importância de os docentes orientarem os alunos na divisão dos quadrinhos e, em um momento posterior, na avaliação dos desenhos, isto é, se as produções dos alunos atenderam aos dados solicitados (FRAGUAS et al., 2021).

Silva Júnior et al. (2020) analisam, por meio de revisão bibliográfica e de uma abordagem do tipo qualitativa, a utilização de HQs na área de Ciências da Natureza. Os autores ressaltam que a utilização desse recurso enseja o desenvolvimento do letramento cientifico, porém pressupõe que o docente realize uma prévia sistematização dos conceitos que serão abordados (SILVA JÚNIOR et al., 2020).

Com o intuito de examinarem se as HQs podem auxiliar a discussão de conceitos científicos e de conteúdos do Ensino de Ciências, em conformidade com o disposto na Base Nacional Comum Curricular, os autores analisaram duas tirinhas da HQs da Mafalda e duas tirinhas da HQ do Armandinho (SILVA JÚNIOR et al., 2020). Os autores abordam que as HQs podem ser utilizadas para a implementação de metodologias ativas no Ensino de Ciências. À vista disso, indicam que a utilização pedagógica de HQs, enquanto gênero textual rico em detalhes, fomenta a leitura e, por consequência, a aprendizagem significativa dos conceitos abordados (SILVA JÚNIOR et al., 2020).

Ao analisarem especificamente o Ensino de Ciências da Natureza, os autores indicam que a utilização pedagógica de HQs exige que o professor aborde, de maneira crítica e reflexiva, as falas e as possíveis interpretações dos alunos (SILVA JÚNIOR et al., 2020). Em adicional, releva-se que a utilização dessa ferramenta deve ser articulada com práticas pedagógicas que propiciem a atuação ativa dos alunos no processo de aprendizagem (SILVA JúNIOR et al., 2020).

Portanto, os autores concluem que o uso de HQs no Ensino de Ciências da Natureza proporciona que os alunos compreendam as especificidades da linguagem dessa área de conhecimento, contribuindo, dessa forma, para o letramento científico (SILVA JúNIOR et al., 2020). Ademais, percebem que as tirinhas analisadas possibilitam a reflexão crítica das problemáticas atuais, assim como contribuem para a proficiência leitora (SILVA JÚNIOR; SILVA et al., 2020). 


\section{HQs no Ensino de Química}

Preussler e Fucks (2021) analisaram a utilização da reciclagem de resíduos ou materiais eletrônicos como tema gerador para o desenvolvimento de práticas educativas no Ensino de Química. A proposta educativa foi direcionada para o Ensino Médio e teve como fundamento teórico e metodológico a perspectiva freireana (PREUSSLER; FUCKS, 2021).

A partir de uma revisão da literatura, os autores definiram a utilização de experimentação e de HQs como duas estratégias didáticas que propiciavam as discussões de questões socioambientais no Ensino de Química (PREUSSLER; FUCKS, 2021). Para os autores, as estratégias propostas permitem a ampliação da compreensão dos conteúdos abordados, assim como a reflexões a partir do tema gerador (PREUSSLER; FUCKS, 2021).

Preussler e Fucks (2021) frisam que a profícua existência de propostas pedagógicas pautadas na utilização de HQs no Ensino de Química pode ser relacionada a não inserção dessa estratégia na formação inicial dos docentes (PREUSSLER; FUCKS, 2021). Também concluem que a construção coletiva de HQs deve ser compreendida como uma prática inovadora no Ensino de Química, pois possibilita a participação ativa dos discentes no processo de aprendizagem (PREUSSLER; FUCKS, 2021).

Por fim, Preussler e Fucks (2021) destacam que a utilização da elaboração de HQs como estratégia pedagógica para a abordagem de questões relacionadas à reciclagem do lixo eletrônico contribui para que os alunos reflitam, de maneira crítica e dialógica, a respeito do contexto no qual estão inseridos (PREUSSLER; FUCKS, 2021). Ainda observam que a combinação entre texto e imagens proporciona a compreensão e contextualização dos conteúdos abordados e fomenta a criatividade e a imaginação dos discentes (PREUSSLER; FUCKS, 2021).

Sales (2020) analisa a realização de uma estratégia de ensino direcionada para a aprendizagem em Química, no contexto do ensino remoto emergencial. A proposta foi fundamenta na utilização de metodologias ativas e realizada com discentes de cursos técnicos de Redes de Computadores, Eletrotécnica e Mecatrônica (SALES, 2020). O objetivo proposto pelo autor foi que os discentes contextualizassem os conteúdos da disciplina de Química a partir de atividades realizadas em casa (SALES, 2020). Desse modo, o autor ressalta que as atividades deveriam ser "[...] vinculadas a uma das seguintes categorias: Receitas em casa, Fato ou Fake?, Criatividade em Foco ou Experimentando em Casa" (SALES, 2020, p. 6).

Ao analisar as atividades vinculadas à categoria "Criatividade em foco", o autor aponta que os estudantes elaboraram charges e HQs (SALES, 2020). Nesse sentido, o autor sublinha que as narrativas criadas pelos alunos buscaram relacionar os conteúdos de química com o cotidiano vivenciado (SALES, 2020). Desse modo, realça-se que uma $\mathrm{HQ}$ discutiu a função orgânica do etanol, a partir de uma narrativa que pontua os malefícios do elevado consumo de bebidas alcoólicas (SALES, 2020).

Destarte, o autor conclui que a estratégia contribuiu para uma maior interação entre discentes e docentes e para a contextualização dos conteúdos teóricos abordados em sala de aula (SALES, 2020). Sales avulta que a utilização da criação de HQ ou charges contribuiu para o aumento da aprendizagem e contextualização de conceitos científicos abordados no Ensino de Química (SALES, 2020).

Silva et al. (2021) discorreram acerca de uma proposta didática que utiliza a elaboração de HQs para promover o aprofundamento de temáticas ambientais no Ensino Médio. A proposta foi oriunda das vivências no Estágio Supervisionado do 
curso de Licenciatura em Química e foi implementada no contexto do ensino remoto (SILVA et al., 2021).

No processo de elaboração da proposta, os autores selecionaram o eixo temático Química Orgânica - Grupos Funcionais e utilizaram as ferramentas on-line de edição disponíveis no site "MeuGibi.com" para a confecção da HQ (SILVA et al., 2021). A narrativa da HQ é pautada na interação entre personagens de diferentes faixas etárias e tem o enredo focado na contaminação do rio que passa próxima à casa da avó do protagonista da história, um menino chamado Bruno (SILVA et al., 2021).

Os autores utilizaram diálogos com uma linguagem informal objetivando permitir a utilização da proposta e a discussão no que concerne aos conteúdos de Química e Ciências no Ensino Médio e nos anos finais do Ensino Fundamental (SILVA et al., 2021). A versão final da HQ foi intitulada "Ao combate da Química do mal" e objetiva que os alunos utilizem os conhecimentos e conceitos científicos para compreenderem os problemas ambientais relacionados à Química (SILVA et al., 2021).

A utilização de $\mathrm{HQ}$ é caracterizada pelos autores como uma estratégia pedagógica não tradicional que pode contribuir para que a internalização do conhecimento científico seja aliada a formação social crítica dos alunos (SILVA et al., 2021). Nesse sentido, salientam que o ensino lúdico, implementado por meio da utilização de HQs, proporciona a curiosidade a respeito dos conteúdos, assim como a problematização das temáticas ambientais abordadas (SILVA et al., 2021).

Segundo concluíram os autores, a proposta de utilização da $\mathrm{HQ}$ revelou-se pertinente para ser aplicada em diferentes momentos do processo de ensino, sendo frisada a sua utilização como forma de avaliar a aprendizagem dos alunos (SILVA et al., 2021). Observaram, que as $H Q$ s não devem ser compreendidas como substitutas dos livros didáticos, porem são um recurso didático adicional que pode ser inserido no ensino remoto ou presencial (SILVA et al., 2021).

Ao discutirem o uso de $\mathrm{HQ}$ no ensino de Química e Ciências, os autores identificaram a importância de a formação dos professores ser pautada na utilização de novas metodologias de ensino e recursos pedagógicos (SILVA et al., 2021). Também concluíram que as propostas de criação e utilização de HQs ensejaram uma maior interação entre os alunos e o professor (SILVA et al., 2021). Outra questão apontada pelos autores foi que a utilização de ilustrações e de uma linguagem informal nas HQs contribui para a compreensão dos conteúdos e conceitos abordados pelos alunos de diferentes níveis de ensino.

\section{BREVES CONSIDERAÇÕES QUANTO AO USO DE HQS NO ENSINO REMOTO DE CIÊNCIAS DA NATUREZA}

A partir da análise dos artigos selecionados é possível identificar algumas tendências ou características gerais do processo de utilização de HQs, enquanto ferramentas ou recursos pedagógicos, no Ensino remoto de Ciências da Natureza. Frisa-se, todavia, que as considerações pontuadas são decorrentes de propostas específicas, porém entende-se que a revisão bibliográfica permitiu a identificação de reflexões que podem subsidiar a elaboração de posteriores propostas para o modelo de ensino híbrido e/ou para o modelo presencial.

Em um primeiro momento, menciona-se que a revisão da literatura realizada reafirma a perspectiva de utilização de HQs para o ensino de diferentes conteúdos em sala, uma vez que as propostas analisadas nos dez artigos abordam dez assuntos ou conteúdos diferentes. Nesse sentido, ressalta-se que as HQs foram 
utilizadas para a discussão dos seguintes assuntos: conscientização ambiental (OLIVEIRA et al., 2021), pandemia de COVID-19 (AMORIM; COSTA, 2020), funções e características das organelas celulares (TEIXEIRA; BARBOSA, 2021), medidas profiláticas para a diminuição do contágio de doenças que tenham vírus e bactérias como agentes patógenos (FRAGUAS et al., 2021), letramento científico (SILVA JÚNIOR et al., 2020), História da Ciência (GASPERI; EMMEL, 2021), gravidez na adolescência (CUSTÓDIO et al., 2021), função orgânica do etanol (SALES, 2020), reciclagem de sucata eletrônica (PREUSSLER; FUCKS, 2021) e problemas ambientais relacionados à Química (SILVA et al., 2021).

No que diz respeito à forma de uso, constata-se que as propostas desenvolvidas pelos respectivos autores preveem a inserção de HQs no processo de ensino e de aprendizagem a partir de duas configurações. Os trabalhos de Custódio et al. (2021), Gasperi e Emmel (2021), Silva Júnior et al. (2020) e Silva et al. (2021) propõem o uso de HQs elaboradas pelos próprios autores ou de HQs produzidas para fins de entretenimento. Em contrapartida, os trabalhos de Oliveira et al. (2021), Sales (2020), Fraguas et al. (2021), Amorim e Costa (2020), Teixeira e Barbosa (2021) e Preussler e Fucks (2021) apresentam propostas que utilizaram a criação de HQs como uma atividade pedagógica para promoção da aprendizagem dos conteúdos abordados.

Em relação à utilização de HQs previamente produzidas, observa-se que apenas Silva Júnior et al. (2020) propõem o uso de HQs produzidas para fins de entretenimento, HQs dos personagens Mafalda e Armandinho, com o intuito de fomentar a reflexão dos alunos acerca da relação entre os conceitos científicos e os fatos ou acontecimentos cotidianos. Já os trabalhos de Custódio et al. (2021) e Silva et al. (2021) utilização HQs autorais e inéditas criadas pelos próprios autores para uso em um contexto educacional específico.

Essa tendência caracterizada pela produção de HQs para uso didático em conteúdos curriculares da área de Ciências da Natureza também foi demonstrada em levantamento bibliográfico realizado por Camargo e Rivelini-Silva (2017). A partir dos trabalhos de Custódio et al. (2021) e Silva et al. (2021), se destaca a importância de o docente ter um conhecimento das especificidades do gênero textual $H Q$, bem como considerar a faixa etária dos alunos no decorrer do processo de elaboração da HQ. Também se ressalta que o docente deve aliar a discussão do conceito ou conteúdo cientifico à elaboração de uma narrativa acessível e que promova a curiosidade dos alunos.

No que concerne à utilização de HQs produzidas fora de um contexto educacional, o trabalho de Silva Júnior et al. (2020) ressalta a importância de o professor avaliar se o material será adequadamente inserido no planejamento pedagógico proposto. Nesse sentido, o docente deve analisar se as informações presentes na $\mathrm{HQ}$ contribuíram para as discussões em sala de aula, assim como complementaram o ensino e a aprendizagem (CAMARGO; RIVELINI-SILVA, 2017; SILVA JÚNIOR et al., 2020).

A revisão da literatura permite inferir que utilização de HQs previamente elaboradas pressupõe que o docente reserve um momento para os alunos realizarem a leitura do material (CUSTÓDIO et al, 2021; SILVA et al., 2021; SILVA JÚNIOR et al., 2020). No contexto do ensino remoto emergencial ou do ensino híbrido, esse momento destinado à leitura da $\mathrm{HQ}$ pode ser planejado como uma atividade assíncrona ou como uma atividade síncrona. Outra questão identificada a partir dos trabalhos de Custódio et al. (2021), Gasperi e Emmel (2021), Silva Júnior 
et al. (2020) e Silva et al. (2021), foi a necessidade de uma análise da adequabilidade da extensão da $\mathrm{HQ}$ com a faixa etária do público-alvo.

Oliveira et al. (2021), Sales (2020), Fraguas et al. (2021), Amorim e Costa (2020), Teixeira e Barbosa (2021) e Preussler e Fucks (2021) sugerem propostas fundamentadas na elaboração de HQs pelos estudantes, a partir do conteúdo ou assunto abordado em sala de aula. Por conseguinte, verifica-se que os mencionados autores utilizam a elaboração da $\mathrm{HQ}$ para auxiliar a compreensão do conteúdo ou assunto previamente abordado e/ou avaliar a aprendizagem dos alunos.

As propostas de criação das HQs previam tanto a utilização de ferramentas on-line ou recursos tecnológicos (smartphones, tablets, computadores etc.), como a elaboração através de desenhos coloridos. A utilização de recursos tecnológicos no processo de elaboração das HQs pode ser relacionada, de certa forma, à inserção de TICs no processo de ensino e de aprendizagem resultante da implementação do modelo remoto de ensino.

Em adição, menciona-se que a solicitação de elaboração através de desenhos foi relacionada ao fato de parte dos alunos não disporem de recursos tecnológicos para produção do material solicitado fora dos horários de aula. À vista disso, observa-se a necessidade de o professor estabelecer se a atividade de criação da $\mathrm{HQ}$ será individual ou em grupo e analisar se os alunos possuem os recursos necessário para sua realização (AMORIM; COSTA, 2020; TEIXEIRA; BARBOSA, 2021).

No tocante a essa questão, Teixeira e Barbosa (2021) indicam que a principal dificuldade enfrentada para a execução da proposta foi o acesso dos alunos aos recursos necessário para criação da $\mathrm{HQ}$. De maneira adicional, assinalam que a falta de experiência com o manuseio dos recursos ou dispositivos tecnológicos foi outra dificuldade enfrentada pelos alunos. Nessa perspectiva, permitir a criação através de desenhos é necessário, principalmente, no modelo de ensino remoto para garantir que todos os discentes possam executar a atividade (AMORIM; COSTA, 2020; TEIXEIRA; BARBOSA, 2021).

De maneira complementar, detectou-se que a avaliação das HQs criadas pelos alunos deve considerar os aspectos relacionados à adequada produção dos textos, bem como o domínio do conteúdo abordado na narrativa construída. Nessa perspectiva, sublinha-se que a avaliação deve considerar se os elementos característicos de uma $\mathrm{HQ}$ estão presentes nas criações dos alunos (AMORIM; COSTA, 2020; TEIXEIRA; BARBOSA, 2021).

Ainda sobre a avaliação, é possível inferir a importância do professor, em propostas voltadas para o uso de HQs previamente elaboradas ou para a criação de HQs pelos alunos, verificar o retorno da turma a respeito da proposta realizada. Desse modo, pontua-se que, de maneira geral, que os trabalhos analisados propunham a aplicação de questionários para identificar as impressões dos alunos no que diz respeito à proposta de uso das HQs.

Por fim, é necessário frisar que a utilização de HQs no Ensino de Ciências da Natureza pressupõe que o docente tenha o domínio das especificidades de gênero textual para que possa orientar os alunos nos processos de elaboração das narrativas e de construção gráfica dos quadrinhos. Adicionalmente, constatou-se que a utilização de HQs no ensino remoto emergencial exige que o docente tenha experiência no manuseio dos recursos ou dispositivos tecnológicos utilizados para a elaboração dos materiais e/ou para o envio das criações do professor para o aluno e/ou do aluno para o professor. 


\section{CONSIDERAÇÕES FINAIS}

Em resumo, a realização do presente artigo apresentou os resultados da revisão da literatura sobre a utilização de HQs no ensino remoto de Ciências da Natureza. Constatou-se as possibilidades de inserção das HQs na contextualização didático-pedagógica, na aprendizagem dos conteúdos de maneira lúdica, assim como para a articulação e a contextualização dos conceitos científicos estudados com narrativas que retratassem situações concretas e cotidianas aos discentes.

Concluiu-se que a utilização de $\mathrm{HQs}$ no ensino remoto de Ciências da Natureza foi, em um maior quantitativo dos artigos analisados, centrada na elaboração desses matérias pelos próprios alunos. Nesse sentido, se inferiu que a criação de HQs pelos alunos pode tanto complementar a compreensão dos conteúdos abordados em sala de aula como ser uma atividade direcionada para a avaliação da aprendizagem.

Ademais, notou-se uma tendência caracterizada pela utilização de HQs elaboradas pelos próprios docentes e para contextos pedagógicos específicos. Desse modo, pode-se relacionar essa tendência ao fato dos conteúdos ou conceitos científicos não fazerem parte da maioria das narrativas de HQs produzidas para contextos não educacionais, o que contribuiu para a reduzida inserção destas no Ensino de Ciências da Natureza.

Em adicional, observou-se que a avaliação das HQs produzidas pelos alunos deve considerar os aspectos relacionados à construção textual e gráfica, assim como se a narrativa aborda os conteúdos discutidos em sala de aula de maneira adequada e correta. Também é importante mencionar que as atividades de criação, no modelo de ensino remoto, devem oportunizar a utilização de ferramentas on-line e dispositivos tecnológicos ou a elaboração de desenhos, pois os alunos podem não ter acesso aos recursos necessários para criação da $\mathrm{HQ}$.

Isto posto, reconheceu-se que o uso de HQs, enquanto recurso pedagógico, no contexto da pandemia pressupôs dos docentes o domínio das especificidades que caracterizam o mencionado gênero textual e o conhecimento dos recursos ou dispositivos tecnológicos empregados na criação e compartilhamento destas.

Para os futuros estudos, indica-se a importância de pesquisas que abordem a utilização de HQs no ensino remoto de conteúdos curriculares de outras áreas de conhecimento. Ainda, se aponta a necessidade de trabalhos sobre o uso de HQs elaboradas em contextos não educacionais no Ensino de Ciências da Natureza.

\section{REFERÊNCIAS}

ALVES, V. da S.. Histórias em quadrinhos: a imagem diante do leitor e a apreensão do significado. Literartes, v. 1, n. 8, 2018. Disponível em: < https://doi.org/10.11606/issn.2316-9826.literartes.2018.139925>. DOI: 10.11606/issn.2316-9826. literartes.2018.139925. Acesso em: 03 nov. 2021.

AMORIM, D. C.; COSTA, C. J. de S. A.. Estratégias para o ensino da Covid-19 utilizando aplicativos de histórias em quadrinhos. Revista Intersabseres, v. 15, n. 36, p. 556-580, 2020. Disponível em: < https://www.revistasuninter.com/intersaberes/index.php/revista/article/view/1989/414 459 >.Acesso em: 03 nov. 2021.

BIBE-LUYTEN, S. M.. O que é história em quadrinhos. Brasiliense, 1985. 
BRASIL. Ministério da Educação. Base Nacional Comum Curricular. Brasília: MEC, $2018 . \quad$ Disponível em: http://basenacionalcomum.mec.gov.br/images/BNCC_EI_EF_110518_versaofinal_sit e.pdf. Acesso em: 10 out. 2021.

BRASIL. Ministério da Educação. CAPES. Documento Orientador de APCN Área 46. Brasília: MEC. 2019. Disponível em: <https://www.gov.br/capes/pt-br/centrais-deconteudo/ensino1.pdf>. Acesso em: 10 nov. 2021.

BRASIL. Ministério da Educação. Conselho Nacional de Educação. Parecer 19/2020. Reexame do Parecer CNE/CP no 15, de 6 de outubro de 2020, que tratou das Diretrizes Nacionais para a implementação dos dispositivos da Lei no 14.040 , de 18 de agosto de 2020, que estabelece normas educacionais excepcionais a serem adotadas durante o estado de calamidade pública reconhecido pelo Decreto Legislativo $n^{\circ}$ 6, de 20 de março de 2020. Brasília, 2020. Disponível em: $<$ http://portal.mec.gov.br/index.php?option=com_docman\&view=download\&alias=167 131-pcp019-20\&category_slug=dezembro-2020-pdf\&ltemid=30192>. Acesso em: 29 nov. 2021.

CAMARGO, S. C.; RIVELINI-SILVA, A. C.. Histórias em quadrinhos no ensino de ciências: um olhar sobre o que foi produzido nos últimos doze anos no ENEQ e ENPEC. ACTIO Docência em Ciências, v. 2, n. 3, p. 133-150, 2017. Disponível em: < http://dx.doi.org/10.3895/actio.v2n3.6818>. DOI: 10.3895/actio.v2n3.6818. Acesso em: 30 out. 2021.

CARLAN, F. A.; SEPEL, L. M. N.; LORETO. É. L. Explorando diferentes recursos didáticos no Ensino Fundamental: uma proposta para o ensino de célula. Acta Scientiae, 15(2), 338-353, 2013. Disponível em: < http://posgrad.ulbra.br/periodicos/index.php/acta/article/view/265 >. Acesso em: 3 nov. 2021.

CAVALCANTE, K. S. B. SILVA, F. C.; MACIEL, A. P.; LIMA JÚNIOR, J. A.; RIBEIRO, J. S. dos S.; SANTOS, P. J. C. dos et al. Educação ambiental em histórias em quadrinhos: recurso didático para o ensino de ciências. Química nova na escola, v. 37, n. 4, p. 270-277, 2015. Disponível em: <http://qnesc.sbq.org.br/online/qnesc37_4/06-RSA-56-12.pdf>. Acesso em: 03 nov. 2021.

COSTA, L. A. C. Desafios e avanços educacionais em tempos da COVID-19: a docência no Ensino Remoto em cursos de Engenharia. Revista de Estudos e Pesquisas sobre Ensino Tecnológico (EDUCITEC), v. 6, p. e152920-e152920, 2020. Disponível em: <https://doi.org/10.31417/educitec.v6.1529>. DOI: 10.31417/educitec.v6.1529. Acesso em: 28 out. 2021.

CRUZ, R. M.; BORGES-ANDRADE, J. E.; MOSCON, D. C. B.; MICHELETTO, M. R. D.; ESTEVES, G. G. L. et al. COVID-19: emergência e impactos na saúde e no trabalho. Revista Psicologia Organizações e Trabalho, v. 20, n. 2, p. I-III, 2020. Disponível em: <http://dx.doi.org/10.17652/rpot/2020.2.editorial>. DOI: 10.17652/rpot/2020.2.editorial. Acesso em: 3 nov. 2021. 
CUSTÓDIO, C. G; LEONARDO, F.; NIERO, H. B.; TAGNIN, L. H.; BERTONHA, L. L.; SOUSA, R. da S. et al. Educação sexual no ensino básico: o estudante de medicina como educador. Revista Eletrônica Acervo Saúde, v. 13, n. 2, p. e5501-e5501, 2021. Disponível em: < https://doi.org/10.25248/reas.e5501.2021>. DOI: 10.25248/reas.e5501.2021. Acesso em: 13 out. 2021.

DELFINO, F. C. dos S.; SILVA, S. de C.; TEIXEIRA, R. M. L.; SILVA, C. R. O trabalho docente no cenário da pandemia: relato de experiência sobre as práticas pedagógicas no ensino remoto. Revista Eletrônica Arma da Crítica, n.14, dez, 2020.

Disponível em:

http://repositorio.ufc.br/bitstream/riufc/57883/1/2020_art_fcsdelfino_et_al.pdf Acesso em: 10 nov. 2021.

FEITOZA, T. M. O.; CHAVES, A. M.; MUNIZ, G. T. S.; CRUZ, M. C. C., CUNHA JUNIOR, I. F. Comorbidades e COVID-19. Revista Interfaces: Saúde, Humanas e Tecnologia, v. 8, n. 3, p. 711-723, 2020. Disponível em: <http://dx.doi.org/10.16891/2317-434X.v8.e3.a2020.pp711-723>.

DOI: 10.16891/2317-434X.v8.e3.a2020.pp711-723. Acesso em: 13 jun. 2021.

FERREIRA, D. H. L.; BRANCHI, B. A.; SUGAHARA, C. R. Processo de ensino e aprendizagem no contexto das aulas e atividades remotas no Ensino Superior em tempo da pandemia Covid-19. Revista práxis, v. 12, n. 1 (sup), 2020. Disponível em: $<$ http://revistas.unifoa.edu.br/index.php/praxis/article/view/3464>. Acesso em: 3 nov. 2021.

FRAGUAS, T.; GONZALEZ, C. E. F.; MARQUES, R.. VÍRUS: sequência didática para o Ensino de Ciências pós pandemia. Experiências em Ensino de Ciências, v. 16, n. 1, p. 596-611, 2021. Disponível em: < https://fisica.ufmt.br/eenciojs/index.php/eenci/article/view/824>. Acesso em: 13 nov. 2021.

FREITAS FILHO, J. R.; SOUZA, F. A. M. de; NUNES, A. M.; FREITAS, J. R. de. Relato de uma experiência no ensino virtual de Química Orgânica: revisitando diferentes estratégias pedagógicas. Experiências em Ensino de Ciências, v. 16, n. 2. p. 560-583, 2021. Disponível em: < https://fisica.ufmt.br/eenciojs/index.php/eenci/article/view/941>. Acesso em: 13 nov. 2021.

GALVÃO, M. C. B.; RICARTE, I. L. M. Revisão sistemática da literatura: conceituação, produção e publicação. Logeion: Filosofia da informação, v. 6, n. 1, p. 57-73, 2019. Disponível em: <https://doi.org/10.21728/logeion.2019v6n1.p57-73>. DOI: 10.21728/logeion.2019v6n1.p57-73. Acesso em: 03 nov. 2021.

GARCIA, L. P.; DUARTE, E. Intervenções não farmacológicas para o enfrentamento à epidemia da COVID-19 no Brasil. Epidemiologia e Serviços de Saúde, v. 29, p. e2020222, 2020. Disponível em: <https://doi.org/10.32811/259544822020v3sup1p266>. DOI: 10.32811/25954482-2020v3sup1p266. Acesso em: 13 out. 2021. 
GASPERI, A. M.; EMMEL, R.. Metodologias ativas com o uso de TIC mistas nos processos de ensino e de aprendizagem de HC com HQ. Cadernos de Educação Básica, v. 6, n. 2, p. 185-194, 2021. Disponível em: < http://dx.doi.org/10.33025/ceb.v6i2.3205>. DOI: 10.33025/ceb.v6i2.3205. Acesso em: 13 nov. 2021.

IANESKO, F.; ANDRADE, C. K. de; FELSNER, M. L.; ZATTA, L.. Elaboração e aplicação de histórias em quadrinhos no ensino de ciências. Experiências em Ensino de Ciências, v. 12, n. 5, p. 105-125, 2017. Disponível em: $<$ https://fisica.ufmt.br/eenciojs/index.php/eenci/article/view/642>. Acesso em: 03 nov. 2021.

LEMOS, P. B.; JUCÁ, S. C.; SILVA, S.; SILVA, J. F. . Impactos da Pandemia de Pandemia de COVID-19 para o ensino de Engenharias.Enciclopédia Biosfera , [S. I.], v. 18, n. 37, 2021. Disponível em: https://conhecer.org.br/ojs/index.php/biosfera/article/view/5319. 10.18677/EnciBio_2021C22. Acesso em: 15 nov. 2021.

LIU, A. S.; SILVA, R. de C.; LIMA, L. dos S.. As histórias em quadrinhos como materiais didáticos alternativos no Ensino de Ciências. Revista CompartilharReitoria, v. 4, n. 1, p. 73-78, 2019. Disponível em: $<$ https://ojs.ifsp.edu.br/index.php/compartilhar/article/view/1201>. Acesso em: 13 out. 2021.

MELO, K. C.; MEDEIROS, A. F. de; SILVA, A. A. de. Uma linguagem alternativa no ensino escolar: as histórias em quadrinhos na mediação do ensino e aprendizagem da Geografia. Ateliê Geográfico, v. 7, n. 1, p. 260-283, 2013. Disponível em: < https://doi.org/10.5216/ag.v7i1.18965>. DOl: 10.5216/ag.v7i1.18965. Acesso em: 13 jun. 2021.

MENDES, K. D. S.; SILVEIRA, R. C. de C. P.; GALVÃO, C. M.. Integrative literature review: a research method to incorporate evidence in health care and nursing. Texto \& Contexto-Enfermagem, v. 17, p. 758-764, 2008. Disponível em: < https://doi.org/10.1590/S0104-07072008000400018>. DOI: 10.1590/S010407072008000400018 . Acesso em: 18 out. 2021.

OLIVEIRA, A. R. M. F. de; SOUZA, A. da S.; SILVA, A. P. P. da; SOUZA, K. T. de; JESUS, K. E. S. de; JESUS, M. K. S. de. Educação Ambiental: ações e experiências em espaço educativo não-formal em tempos de pandemia. Revista Macambira, v. 5, n. 1, p. e051003-e051003, 2021. Disponível em: <https://doi.org/10.35642/rm.v5i1.556>. DOI: 10.35642/rm.v5i1.556. Acesso em: 27 out. 2021.

PREUSSLER, V. T.; FUCKS, P. M.. A reciclagem de sucata eletrônica como tema gerador de práticas educativas no nível médio do Ensino de Química. Revista Insignare Scientia-RIS, v. 4, n. 3, p. 504-521, 2021. Disponível em: < https://doi.org/10.36661/2595-4520.2021v4i3.12139>. DOI: 10.36661/25954520.2021v4i3.12139. Acesso em: 17 out. 2021. 
SALES, P. F. de. "Químiemcasa": aspectos de um processo de ensino para a aprendizagem de Química em épocas de pandemia. Research, Society and Development, v. 9, n. 11, p. e83391110420-e83391110420, 2020. Disponível em: <https://doi.org/10.33448/rsd-v9i11.10420>. DOI: 10.33448/rsd-v9i11.10420. Acesso em: 13 out. 2021.

SANTOS JÚNIOR, V. B.; MONTEIRO, J. C. S. Educação e covid-19: as tecnologias digitais mediando a aprendizagem em tempos de pandemia. Revista EncantarEducação, Cultura e Sociedade, v. 2, p. 01-15, 2020. Disponível em : <https://www.revistas.uneb.br/index.php/encantar/article/view/8583>. Acesso em: 3 nov. 2021.

SANTOS, M. O. dos; GANZAROLLI, M. E.. Histórias em quadrinhos: formando leitores. Transinformação, v. 23, p. 63-75, 2011. Disponível em: $<$ https://www.scielo.br/j/tinf/a/D9KdmXLWyZcPhMcvH5cgpSg/?lang=pt\&format=pdf >. Acesso em: 20 out. 2021.

SANTOS, R. E.; VERGUEIRO, W.. Histórias em quadrinhos no processo de aprendizado. EcooS-Revista Científica, São Paulo, n.27, p.81-95, 2012. Disponível em:https://periodicos.uninove.br/index.php?journal=eccos\&page=article\&op=view\&pa th\% 5B\%5D=3498. Acesso em: 29 out. 2021.

SILVA, D. S. C.; SANTOS, M. B.; SOARES, M. J. N. Impactos causados pela COVID-19: um estudo preliminar. Revista Brasileira de Educação Ambiental (RevBEA), v. 15, n. 4, p. 128-147, 2020. Disponível em: <https://doi.org/10.34024/revbea.2020.v15.10722>.

10.34024/revbea.2020.v15.10722. Acesso em: 13 jun. 2021.

SILVA JÚNIOR, E. A. da; SILVA, C. F. P. da; BERTOLDO, S. R. F.. Educação em tempos de pandemia: o uso da ferramenta podcast como estratégia de ensino. Tecnia, v. 5, n. 2, p. 31-51, 2020. Disponível em: < http://revistas.ifg.edu.br/tecnia/article/view/815>. Acesso em: 3 nov. 2021.

SILVA, L. L. da; ALVES, T. R. de S.; DANTAS, L. F. S.. A História em Quadrinhos como proposta didática para o ensino de Química Orgânica: um relato de experiência. Revista Ensino, Saúde e Biotecnologia da Amazônia, p. 68-79, 2021. Disponível em: <https://periodicos.ufam.edu.br/index.php/resbam/article/view/8203>. Acesso em: 23 out. 2021.

TEIXEIRA, S. A.; BARBOSA, J. N.. Produção de Histórias em Quadrinhos on-line na abordagem interdisciplinar de ensino de Biologia e Linguagens. Revista Letras Raras, v. 10, n. 2, p. 44-68/Eng. 44-68, 2021. Disponível em: <http://dx.doi.org/10.35572/rlr.v10i2.2088 >. DOI: 10.35572/rlr.v10i2.2088. Acesso em: 13 out. 2021.

VERGUEIRO, W.. A linguagem dos quadrinhos: uma "alfabetização" necessária. In: RAMA, Ângela; VERGUEIRO, Waldomiro. (org.). Como usar as histórias em quadrinhos na sala de aula. 4. ed. São Paulo: Contexto, 2010. 
VENTURI, T.; SOUZA, A. M. G. de; UMERES, I. C.; LOHMANN, L. A. D.. Projeto Licenciar Biologia: Educação em Saúde no Ensino de Ciências. Extensão em Foco, n. 23, 2021. Disponível em: < http://dx.doi.org/10.5380/ef.v0i20>. DOI: dx.doi.org/10.5380/ef.v0i20. Acesso em: 13 out. 2021.

XAVIER, G. K. R. da S.. Histórias em quadrinhos: panorama histórico, características e verbo-visualidade. Revista Darandina, p. 1-20, 2017. Disponível em: < https://doi.org/10.34019/1983-8379.2017.v10.28128 >. DOI: $10.34019 / 1983-$ 8379.2017.v10.28128. Acesso em: 13 nov. 2021. 